\title{
Molecular characterization of SCARECROW (CSSCR) gene expressed during somatic embryo development and in root of cucumber (Cucumis sativus $\mathbf{L}$.)
}

\author{
Anita Wiśniewska - Anna Pietraszewska-Bogiel • Sabina Zuzga • \\ Norikazu Tagashira • Barbara Lotocka - Stefan Malepszy • \\ Marcin Filipecki
}

Received: 19 September 2012/Revised: 20 November 2012/Accepted: 12 December 2012/Published online: 28 December 2012

(C) The Author(s) 2012. This article is published with open access at Springerlink.com

\begin{abstract}
Somatic embryogenesis (SE) in plants can be used as a model for studying genes engaged in the embryogenic transition of somatic cells. The CsSCARECROW (CSSCR) gene was previously identified among a panel of genes upregulated after the induction of SE in cucumber (Cucumis sativus). The putative CsSCR protein contains conserved GRAS family domains and is extremely similar to AtSCR from Arabidopsis thaliana. SCR proteins are transcription factors involved in root radial patterning and are required for maintenance of the quiescent centre and differentiation of the endodermis. In comparison with other GRAS proteins from cucumber, phylogenetic analyses showed that CsSCR belongs to the SCR cluster. Increased CSSCR transcript accumulation was detected in somatic embryos and roots. Southern blot
\end{abstract}

Communicated by S. Werbrouck.

Electronic supplementary material The online version of this article (doi:10.1007/s11738-012-1189-2) contains supplementary material, which is available to authorized users.

\section{A. Wiśniewska $(\square)$}

Department of Plant Physiology, Faculty of Agriculture

and Biology, Warsaw University of Life Sciences,

Nowoursynowska 159, 02-776 Warsaw, Poland

e-mail: anita_wisniewska@sggw.pl

\author{
A. Pietraszewska-Bogiel $\cdot$ S. Zuzga $\cdot$ S. Malepszy $\cdot$ \\ M. Filipecki \\ Department of Plant Genetics, Breeding and Biotechnology, \\ Faculty of Horticulture and Landscape Architecture, \\ Warsaw University of Life Sciences, Nowoursynowska 159, \\ 02-776 Warsaw, Poland \\ e-mail: a.pietraszewska@uva.nl \\ S. Zuzga \\ e-mail: sabinazuzga@interia.pl \\ S. Malepszy \\ e-mail: stefan_malepszy@sggw.pl
}

analysis and screening of the draft version of the cucumber genome confirmed the lack of close homologues in this species. CsSCR transcripts were localized by in situ hybridization in undifferentiated cells in the globular and heart stages of somatic embryogenesis, and in the endodermis of torpedo and cotyledonary stage somatic embryos, and developing primary and lateral roots. This localization was supported by the pattern of reporter gene activity driven by the CSSCR promoter in transgenic cucumber organs. These results suggest that CsSCR is likely to act in tissue radial organization during somatic embryogenesis and root development.

Keywords Cucumber - GRAS protein family - Root anatomy $\cdot$ Scarecrow $\cdot S C R \cdot$ Somatic embryogenesis

\section{Abbreviations \\ ECS Embryogenic cell suspension \\ LRP Lateral root primordia \\ SE Somatic embryogenesis}

\author{
M. Filipecki \\ e-mail: marcin_filipecki@sggw.pl \\ Present Address: \\ A. Pietraszewska-Bogiel \\ Section of Molecular Cytology, Swammerdam Institute \\ for Life Sciences, University of Amsterdam, Science Park 904, \\ 1098 XH, Amsterdam, The Netherlands \\ N. Tagashira \\ Faculty of Human Life Science, Hiroshima Jogakuin University, \\ 4-13-1 Ushita-Higashi, Higashiku, Hiroshima 732-0063, Japan \\ e-mail: tagasira@gaines.hju.ac.jp \\ B. Łotocka \\ Department of Botany, Warsaw University of Life Sciences, \\ Nowoursynowska 159, 02-776 Warsaw, Poland \\ e-mail: barbara_lotocka@sggw.pl
}




\section{Introduction}

Somatic embryogenesis (SE) is an important technique for clonal propagation of plants as well as a useful model system for studying developmental processes. SE has been intensely investigated in different plant species, e.g. carrot, wheat and spruce (Fujimura and Komamine 1979; Ahmed and Sagi 1993; Bozhkov et al. 2002), but the molecular mechanisms of this process remain obscure. In our laboratory, we have used cucumber somatic embryogenesis (Wróblewski et al. 1995; Burza et al. 2006) as a model to study differential gene expression during the early stages of cucumber development. To obtain cDNA fragments representing genes that take part in this process, the techniques of differential display (DD) and suppression subtractive hybridization ( $\mathrm{SSH}$ ) have been used (Linkiewicz et al. 2004; Wiśniewska et al. 2012). So far, only a few genes engaged in cucumber somatic embryogenesis have been described: CUS1, CsSEF1, Cs-XTH1 and Cs-XTH3 (Filipecki et al. 1997; Linkiewicz et al. 2004; Malinowski et al. 2004; Grabowska et al. 2009). Among our panel of cucumber cDNAs showing differential expression during SE induction, a homologue of the SCARECROW gene was identified and named Cucumis sativus SCARECROW (CSSCR) (Wiśniewska et al. 2012). The SCARECROW gene from A. thaliana (AtSCR1) belongs to the GRAS family of proteins and functions as a transcription factor (Di Laurenzio et al. 1996). SCR and other GRAS proteins share five characteristic domains: LHRI, VHIID, LHRII, PFYRE and SAW (Pysh et al. 1999).

SCR is involved in root radial patterning in A. thaliana (Di Laurenzio et al. 1996; Benfey et al. 1993; Scheres et al. 1995), and the expression patterns of AtSCR orthologues can suggest a similar function in maize (Lim et al. 2000, 2005), pea (Sassa et al. 2001), rice (Kamiya et al. 2003), Pinus sylvestris (Laajanen et al. 2007) and white lupin (Sbabou et al. 2010). In A. thaliana, SCR and another GRAS family member SHR (SHORT ROOT) play a key role in specification of the cortex and endodermis cell layers, which are located between the epidermis and the pericycle. The Arabidopsis scr mutant has one cell layer with attributes of both the cortex and the endodermis (Di Laurenzio et al. 1996; Benfey et al. 1993; Scheres et al. 1995). SHR functions upstream of $S C R$, but $S C R$ gene expression is also under auto-regulatory control and SCR blocks the movement of SHR through direct protein-protein interaction (Heidstra et al. 2004; Cui et al. 2007).

The aim of this study was the molecular characterization of the CSSCR gene, identified due to its increased expression after the induction of somatic embryo development. The localization of CsSCR transcripts in somatic embryos and roots was achieved by a combination of in situ hybridization and the examination of $C S S C R$ promoter activity in transgenic roots.

\section{Materials and methods}

Plant material

In this study, cucumber (Cucumis sativus L. var. Borszczagowski) was used in experiments to characterize the CsSCR gene. The induction of somatic embryogenesis (SE) process from a cucumber embryogenic cell suspension (ECS) was performed by removing the growth regulator 2,4-dichlorophenoxyacetic acid (2,4-D) from the culture medium, as described by Linkiewicz et al. (2004). From 3rd to 14th day post-SE induction embryos developed from globular to torpedo stages (Linkiewicz et al. 2004).

Cloning of cDNA and genomic CsSCR sequences

The isolation of mRNA, cDNA library construction and plaque screening were performed as described by Grabowska et al. (2009). A DNA probe for cDNA library screening was prepared from the 573-bp cDNA fragment identified by SSH (Wiśniewska et al. 2012). An obtained CSSCR cDNA was then used as the probe for screening a cucumber genomic (EMBL-4) DNA library to identify a clone containing the $5^{\prime}$ untranslated region (missing from the cDNA), an intron and the promoter sequence of the CSSCR gene. The CsSCR intron sequence was amplified from a positive $\lambda$ genomic clone with primers flanking its putative location (5'-CTTGGCCTTCCGTTTGATTTC- $3^{\prime}$ and $5^{\prime}$-CAAGCGTATACCCATCGGAAG- $3^{\prime}$ ), and a fragment of the CsSCR gene containing the upstream regulatory region and $5^{\prime} \mathrm{UTR}$ was amplified from the phage clone using one gene-specific primer (5'-TTTCTGGCTGTGTGT ATGGGG- $3^{\prime}$ ) and a second binding to a sequence in the right arm of the EMBL-4 vector (5'-GACGAAAACATGC CACAC- $3^{\prime}$ ). Genomic DNA fragments were amplified by PCR using Tth polymerase (BD Biosciences-Clontech), then cloned in vector pCRII-TOPO (TOPO TA Cloning Kit, Invitrogen) and sequenced.

Bioinformatics tools and phylogenetic analyses

Potential upstream regulatory cis-elements were identified using the programs PLACE (Higo et al. 1999), PlantCARE (Lescot et al. 2002) and TRANSFAC (Patch 1.0) (Matys et al. 2003). Alignments of SCR proteins from different species were performed using CLUSTALW2 with default settings (http://www.ebi.ac.uk.clustalw). Statistics of the properties of homopolymeric regions of SCR proteins were 
calculated using pepstats EMBOSS (Rice et al. 2000). Phylogenetic analyses were conducted using MEGA version 4 (Tamura et al. 2007). The accession numbers of the sequences used in this study are listed in Table S1. Cucumber proteins similar to CsSCR were extracted using the blastp algorithm (Altschul et al. 1997) from the predicted protein database of cucumber available at http://csgenome.sggw.pl (Wóycicki et al. 2011). Cucumber polypeptide sequences with a minimum of $40 \%$ similarity to CsSCR and an e-value of below 0.01 were selected. Phylogenetic analyses of the conserved regions of GRAS family proteins using the maximum parsimony (MP) and the minimum evolution (ME) methods were used to infer evolutionary relationships. The MP tree was constructed using the Close-Neighbor-Interchange algorithm with search level 3, in which the initial trees were obtained by the random addition of sequences (10 replicates) (Nei and Kumar 2000). The phylogenetic trees were constructed using the human (Homo sapiens) STAT1 protein as an outgroup. Bootstrap analysis was conducted using 2,000 replicates. CsSCARECROW-like (CsSCL) proteins were named according to their similarity to CsSCR: CsSCL1 is the most and CsSCL36, the least similar to CsSCR.

\section{Real-time RT-PCR}

Total RNA was isolated from cucumber leaf, root, female flower, somatic and mature zygotic embryos, and ECS by extraction with Trizol (Invitrogen), according to the recommended procedure. Real-time RT-PCR was performed using a LightCycler and SYBR Green I RNA Amplification Kit (Roche) according to the manufacturer's instructions. Reverse transcription was performed at $55{ }^{\circ} \mathrm{C}$ for $10 \mathrm{~min}$. The 341-bp CsSCR fragment was then amplified with specific primers (5'-CTTCCACTAATAGCAACGG and 5'-GACCCTTCGATTACAACTG-3') using a thermocycle with the following parameters: annealing for $10 \mathrm{~s}$ at $56{ }^{\circ} \mathrm{C}$ and extension for $30 \mathrm{~s}$ at $72{ }^{\circ} \mathrm{C}$. Levels of the cDNA in each sample were quantified by the Second Derivative Method using LightCycler Software (Ver. 5.32; Roche). Relative expression of the CsSCR gene was estimated using 25S ribosomal RNA from cucumber as an endogenous control amplified with specific primers (5'-CCAGGT CAGGCGGGACTAC and 5'-CGCAACGGGCTCTCTCA CC- $3^{\prime}$ ). After being normalized to the level of $25 \mathrm{~S}$ rRNA, the CsSCR transcript levels were given relative to that of an ECS (assigned the value of 1). Three technical replicates were performed.

\section{In situ RNA hybridization}

Tissue fixation, embedding, sectioning and in situ hybridization with DIG-labelled sense and antisense single- stranded RNA probes were performed as described by Lincoln et al. (1994). No less than 20 embryos for every developmental stage or root tips were subjected to the microscopic examination. To prepare the template for generating the probes, a 521-bp fragment of the CSSCR cDNA was amplified by PCR with primers $5^{\prime}$-AGCAACT GTTATCAAGGG- $3^{\prime}$ and $5^{\prime}$-AGAAAAAGGCTATAATC A- $3^{\prime}$ and cloned into the vector pCRII-TOPO (Invitrogen). In vitro transcription of this construct with $\mathrm{T} 7$ and SP6 RNA polymerases (Roche) in the presence of digoxigenin11-UTP was used to generate labelled antisense and sense RNA probes.

Plasmid construction, cucumber transformation and GUS staining

A 1,721-bp DNA fragment comprising the CsSCR upstream regulatory region was amplified from phage clone using primers with $5^{\prime}$ extensions, including the recognition sequences for restriction enzymes EcoRI and Bam HI ( $5^{\prime}$-CAG AATTCGGTCCAAATGTTTCACTA- ${ }^{\prime}$ and $5^{\prime}$-CTGGATC CTGAAGGAAAGAAGGAAGT-3), using the BD Advantage $^{\text {TM }} 2$ PCR Enzyme System (BD Biosciences-Clontech). This fragment was purified, digested with the aforementioned enzymes and introduced into the pCambia $1381 \mathrm{Z}$ binary vector (Cambia, Canberra, Australia) that had been cleaved with the same enzymes. The binary vector construct in which the CSSCR promoter region had been fused to the uidA reporter gene and pCAMBIA 1305.1 were introduced into Agrobacterium tumefaciens EHA105 by electroporation.

Cucumber ECS transformation was performed according to Burza et al. (2006). A $2 \mathrm{ml}$ packed cell volume (PCV) of ECS was co-cultured with the transformed Agrobacterium $\left(\mathrm{OD}_{600}\right.$ 0.6), with the addition of acetosyringone $(100 \mu \mathrm{M})$, for 3 days on a rotary shaker $(150 \mathrm{rpm})$ in the dark. Somatic embryos were obtained by plating selected cell lines on hormone-free liquid regeneration medium, containing MS with half-strength macroelements, a full set of microelements, organic components and $15 \mathrm{~g} \mathrm{dm}^{-3}$ sucrose. For embryo conversion, hormone-free 1/2MS-E medium (MS half-strength macroelements, a full set of microelements, organic components with edamin omitted, and $15 \mathrm{~g} \mathrm{dm}^{-3}$ sucrose) solidified with $0.75 \%$ agar (Difco) and supplemented with $200 \mathrm{mg} \mathrm{dm}^{-3}$ timentin (Duchefa), was used. Cultures were placed in a growth chamber at $25{ }^{\circ} \mathrm{C}$ with a light intensity of $54 \mu \mathrm{mol} \mathrm{m} \mathrm{s}^{-2}$ and a $16 \mathrm{~h}$ photoperiod. Subculturing was performed every 3 weeks and only well developed, rooted plants were transferred to soil and acclimated in the greenhouse.

For histochemical GUS staining, plant tissues were bathed in freshly prepared staining solution $[0.05 \mathrm{M}$ phosphate buffer ( $\mathrm{pH}$ 7.2), X-GlcA cyclohexylammonium (Duchefa, $0.1 \% \mathrm{w} / \mathrm{v})$, methanol $(20 \% \mathrm{w} / \mathrm{v})$ and Triton 
$\mathrm{X}-100($ Sigma, $0.1 \% \mathrm{w} / \mathrm{v})]$ for $24 \mathrm{~h}$ at $37{ }^{\circ} \mathrm{C}$ (Jefferson et al. 1987).

Root anatomy analysis

Root tips $(5 \mathrm{~mm})$ from 5-day-old seedlings were fixed separately in a solution containing $2 \%$ glutaraldehyde and $2 \%$ paraformaldehyde in $0.1 \mathrm{M}$ sodium cacodylate buffer ( $\mathrm{pH}$ 6.8), and embedded in epoxy resin (Fluka; equivalent to Epon 812). The samples were then cut into 2- $\mu$ m-thick sections using a Leica JUNG RM 2065 microtome, fixed on glass slides and stained with methylene blue and azure. The stained sections were examined under an Olympus AX70 "Provis" microscope.

Transgenic roots were fixed for $15 \mathrm{~min}$ in a solution containing 0.1 M phosphate buffer ( $\mathrm{pH} 7.2), 0.1 \%$ formaldehyde, $0.1 \%$ Triton X-100 and $0.1 \%$ 2-mercaptoethanol, then washed twice in $0.1 \mathrm{M}$ phosphate buffer plus $0.1 \% 2$-mercaptoethanol, and once in $0.1 \mathrm{M}$ phosphate buffer. Transgenic roots after histochemical GUS staining were fixed in $5 \%$ acetic acid, $5 \%$ formaldehyde and $20 \%$ ethanol for $15 \mathrm{~min}$ and in $50 \%$ ethanol for $10 \mathrm{~min}$, then dehydrated using an ethanol series, embedded in Epon (Fluka) and cut into $20 \mu \mathrm{m}$ sections. Microscopic analysis was performed using Nomarski optics.

\section{Results}

\section{CsSCR gene characterization}

Two independent $1.2-\mathrm{kb}$ CsSCR cDNA clones were isolated from a cDNA library prepared from somatic embryo mRNA. Both clones had incomplete $5^{\prime}$ ends, compared to $S C R$ sequences from other species. One of the isolated cDNAs was then used as a probe to screen a cucumber genomic DNA library. Two independent genomic clones (11 and $5 \mathrm{~kb}$ ) were isolated and sequenced. The obtained CsSCR gene sequence (4,958 bp) consisted of the potential $5^{\prime}$ regulatory region $(1,736 \mathrm{bp})$, the ORF coding for CsSCR (2,577 bp, 858 amino acids) interrupted by one intron
(455 bp), and the $3^{\prime}$ untranslated region (190 bp) (Fig. S1). The complete cDNA and genomic sequences of $C s S C R$ have been deposited in the EMBL database (accession numbers AJ870306 and AJ870307, respectively). The SCR genes of different species share a similar gene architecture. All of them possess a single intron and the positions of the exon/intron boundaries are conserved, as is the size of the second exon (Fig. 1a).

In any nucleotide sequence, it is possible to identify a large number of potential cis-regulatory elements using bioinformatics tools, although detailed analyses are required to confirm their functionality. By screening the 1,736-bp upstream regulatory region of the CsSCR gene with three $c i s$-element recognition programs, we detected a number of potentially interesting sequence motifs: $T G C A A A G$ and $A A C A A A C$, which are necessary for endosperm-specific gene expression (Wu et al. 2000); TATCCA and TATCCAC, responsible for the gibberellin response (Lanahan et al. 1992; Gubler and Jacobsen 1992); ATTTCAAA, an ethylene-responsive element (Itzhaki et al. 1994; Montgomery et al. 1993); CCTTTT, which is found in the promoter of the $\alpha$-amylase gene expressed in embryos and induced by gibberellins (Morita et al. 1998; Mena et al. 2002); and TGCATG and ACGTG, two ABAresponsive elements (Hattori et al. 1992; Hobo et al. 1999) (Tab. S2). Due to the lack of information concerning the length of the $5^{\prime}$ UTR we were unable to determine the position of the TATA box or Inr elements.

\section{Characterization of the CsSCR protein}

The putative amino acid sequence of CsSCR was compared with other SCR proteins (Fig. S2). The C-terminal halves of the compared sequences were highly conserved, while the N-terminal halves were not. The C-terminal part of the putative CsSCR protein consisted of conserved domains characteristic of GRAS family proteins: two leucine heptads (LHRI and LHRII), VHIID, PFYRE and SAW (Fig. 1a). The size variation of the homopolymeric region of SCR proteins is a result of differences in the length of the first exons of their genes. In the homopolymeric region
Fig. 1 a Schematic diagram showing the structure of four $S C R$ genes. SCR genes possess one intron (black line), located in the same position. b Structure of the CsSCR gene showing the location of molecular probes and restriction enzyme sites used in Southern blot analysis (only significant for the interpretation of results of this analysis). $H P R$ homopolymeric region

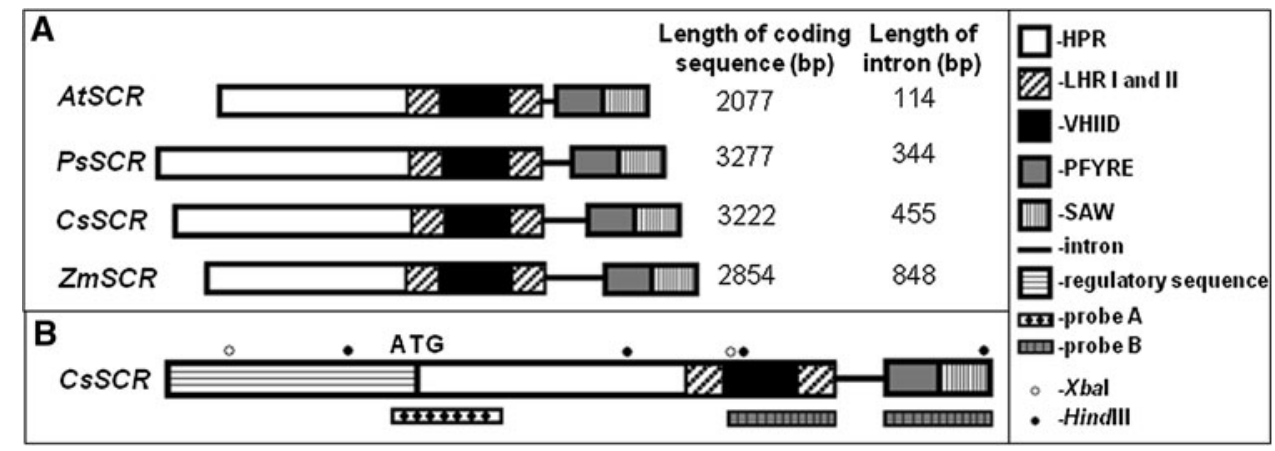




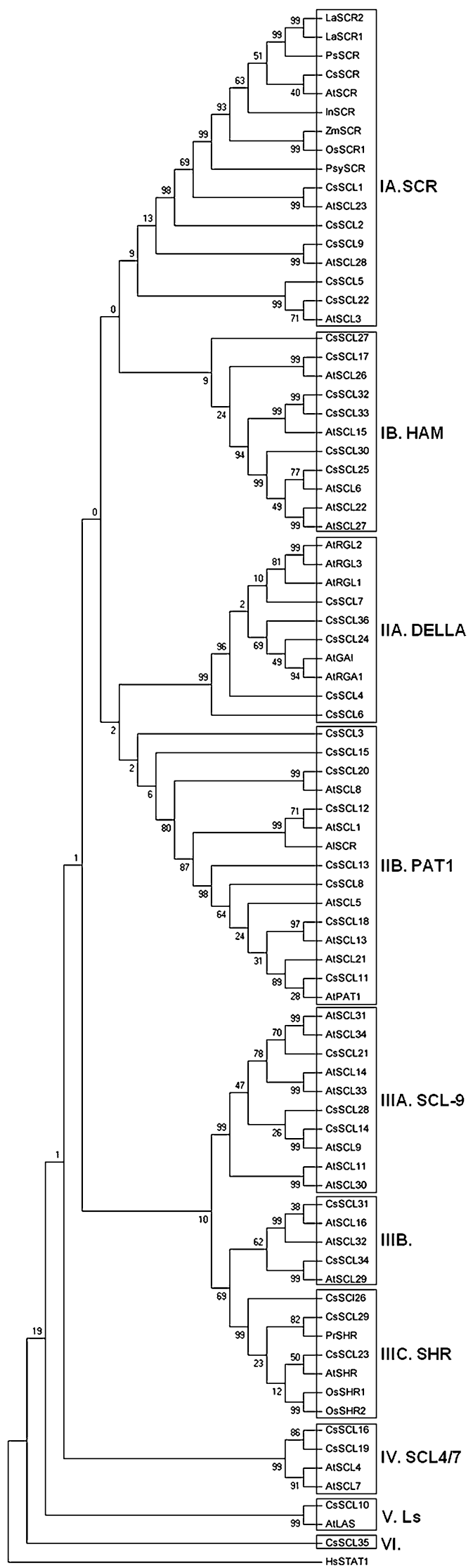

4 Fig. 2 Phylogenetic rooted tree of GRAS proteins from cucumber and other species (see Table S1) constructed from 82 conserved deduced amino acid sequences using the maximum parsimony method. To simplify the visualization, six branches were drawn. Bootstrap values are shown at each node. The human HsSTAT1 protein was used as an outgroup (Bolle 2004)

(HPR) of the putative CsSCR protein (472 amino acids), leucine, serine, proline, alanine and asparagine residues were highly abundant, constituting $11.1,11.1,10.9,8.1$ and $7.1 \%$ of the total, respectively. Similarly, these five amino acids dominate the HPRs of nine related SCR proteins from other species, representing between 36 and $56 \%$ of residues (Tab. S3).

Genomic Southern blot and phylogenetic analyses

Isolated cucumber genomic DNA was digested with the restriction enzymes HindIII, XbaI (sites present in coding sequence), BamHI and XhoI to prepare a Southern blot, which was hybridized with two different $C s S C R$ gene probes (Fig. S1; Fig. 1b, for methods see Supplementary materials). Specific probe A detected single bands, whereas probe B, representing a conserved region, did not cross-hybridize with other genes, showing that there are no closely related homologues of CsSCR in the cucumber genome (Fig. S3). The shorter restriction fragments of HindIII (188 bp) and $\mathrm{XbaI}$ (52 and $149 \mathrm{bp)}$ weekly covered by molecular probes were not detected in the applied stringent washing condition. To estimate the evolutionary relationships among GRAS family members of cucumber, 36 putative Scarecrow-like proteins were selected from the translations database created using the draft version of the recently sequenced cucumber genome (Wóycicki et al. 2011). The cucumber paralogues were compared with the CsSCR protein and other known SCR (Table S1) and SHR proteins from selected plant species. Phylogenetic trees of the conserved C-terminal region of GRAS proteins were constructed using the maximum parsimony (MP) (Fig. 2) and the minimum evolution (ME) (Fig. S4) methods, which gave similar results. In the MP and ME trees, GRAS proteins were grouped into six main branches (I-VI), which differed in position and tree topology, but not in content, with the exception of CsSCL3 and 15 other proteins, which belonged to the IIB branch in the MP tree, but created a separate branch in the ME tree (Fig. S4, star). The groupings of GRAS family proteins were named according to Bolle (2004). All SCR proteins belonged to the same branch (IA) and CsSCR was most closely related to AtSCR. ZmSCR and OsSCR, which originate from monocot species, formed a separate branch, and PsySCR, as a gymnosperm species, was least related to the other analysed proteins. CsSCL24 and CsSCL36 were more closely related to DELLA proteins and belonged to the DELLA subfamily 
(branch IIA). These proteins possess characteristic domains at their N-terminal ends, that are absent in other GRAS members, and act in the negative regulation of GA signalling (Pysh et al. 1999; Silverstone et al. 1998; Peng et al. 1999). The branch IIB contained proteins similar to PAT1 from A. thaliana. PAT1 and SCL13 play a role in the phytochrome A and B signal transduction pathways (Bolle 2004; TorresGalea et al. 2006). The branch IIIC contained SHR proteins. SHR was reported to function together with SCR in endodermis specification (Cui et al. 2007; Helariutta et al. 2000; Nakajima et al. 2001). CsSCL23 was the protein most similar to A. thaliana SHR. The branch V contained CsSCL10, which is similar to AtLAS, a protein required to maintain the axillary meristem in an undifferentiated state (Bolle 2004). CsSCL36 was found to have no close homologues among GRAS family proteins.

\section{Expression of CsSCR in cucumber organs}

For the detection of $S C R$ transcripts in cucumber tissue, real-time RT-PCR was used. Transcript levels were estimated relative to that of an embryogenic cell suspension (ECS), after being normalized to the 25S rRNA level (internal control). High levels of CSSCR transcripts were detected in somatic embryos and roots of adult plants in comparison with the ECS. CSSCR transcripts were also detected in female flowers and leaves, but at lower levels than in SE and roots (Fig. 3).

\section{CsSCR transcript localization in cucumber somatic embryos}

Microscopic examination of tissue sections after in situ hybridization with a specific probe indicated that CsSCR transcript localization in early embryos, equivalent to the zygotic globular stage, was variable. Hybridization signals were observed as patches localized inside the embryo structure or nearer its surface, and in the outermost cell

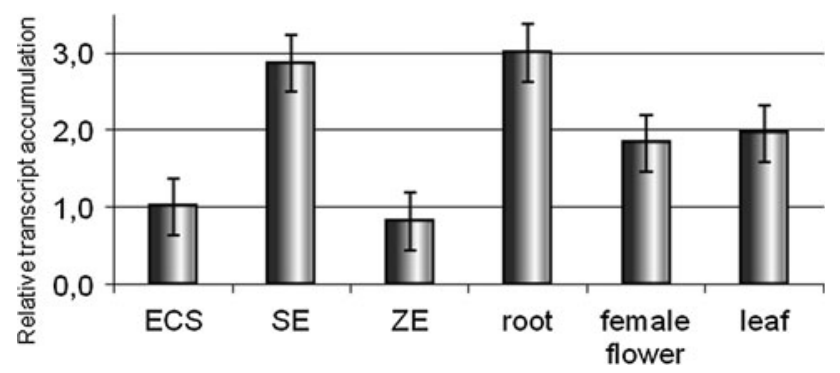

Fig. 3 Expression of the $C S S C R$ gene in various organs of cucumber. Transcript levels analysed by real-time RT-PCR are given relative to that in ECS (the value of 1), after being normalized to the level of $25 \mathrm{~S}$ rRNA. Data are shown as the means $( \pm S E)$ from three independent reactions. ECS embryogenic cell suspension, $S E$ somatic embryos, $Z E$ zygotic embryos layer (Fig. 4a, b). Somatic heart embryos often occurred as a single or coadunate in root pole structures (Fig. 4d). CSSCR expression was observed in the basal parts of heart embryos in an arc-shaped pattern, with the ends located near cotyledon primordia (Fig. 4d, f). In transverse sections, the ends of the arc appeared as patches in the middle of the embryo structure (Fig. 4g). Cucumber torpedo somatic embryos have developed root and two or more cotyledon primordia. Longitudinal sections through torpedo embryos showed a similar CSSCR expression pattern to that seen in heart embryos, i.e. an arc with the ends extending to the cotyledon primordia (Fig. 4h). In a transverse section of mature embryos, specific hybridization was visible as a circle in the inner part of the embryo (Fig. 4i), and in longitudinal sections, this signal was observed in cells corresponding to differentiating endodermis (Fig. $4 \mathrm{j}, \mathrm{k}$ ). In the cotyledon part of mature somatic embryos, no signals were detectable after hybridization with the antisense probe (Fig. 4n). No signals were observed in any samples following hybridization with a sense probe (data are shown only for globular and mature stage somatic embryos, Fig. 4c, e, m).

\section{Histological analysis of cucumber root}

Since cucumber root anatomy was poorly described in the literature, we performed a basic histological study to assist interpretation of our results. In the root, the vascular cylinder was surrounded by several layers of cortex and a single layer of a rhizodermis (Fig. 5). The innermost layer of the cortex was an endodermis and within this, a pericycle composed of a single layer of cells was situated. The number of phloem and xylem bundles was found to vary within a single root or among roots of different cucumber plants. Triarch or tetrarch xylem bundles were observed. The number of cortex layers varied along the length of a primary root or among roots of different plants: between 5 (in the elongation zone) and 7 (in the maturation zone) layers were observed. According to Heimsch and Seago (2008), the cucumber root apical meristem (RAM) has the open organization type OTvD (open, transversal meristem dicot), where the tiers of initials are disorganized as opposed to the closed meristem, where they are arranged in distinct layers. The putative localization of quiescent centre (QC) is shown in Fig. 5 and putatively it consisted of 10-20 cells. The endodermis cell layer and internal layer of cortex originate from the same initial cell located in the closed neighbourhood of QC. The rhizodermis cell layer is derived from lateral rootcap-epidermal initials. Below the QC the columella root cap is located. The development of lateral root primordia (LRP) is shown in Fig. 6i, j. In the early stages of the initiation of LRP, many anticlinal divisions in the pericycle cells were observed, followed by periclinal 


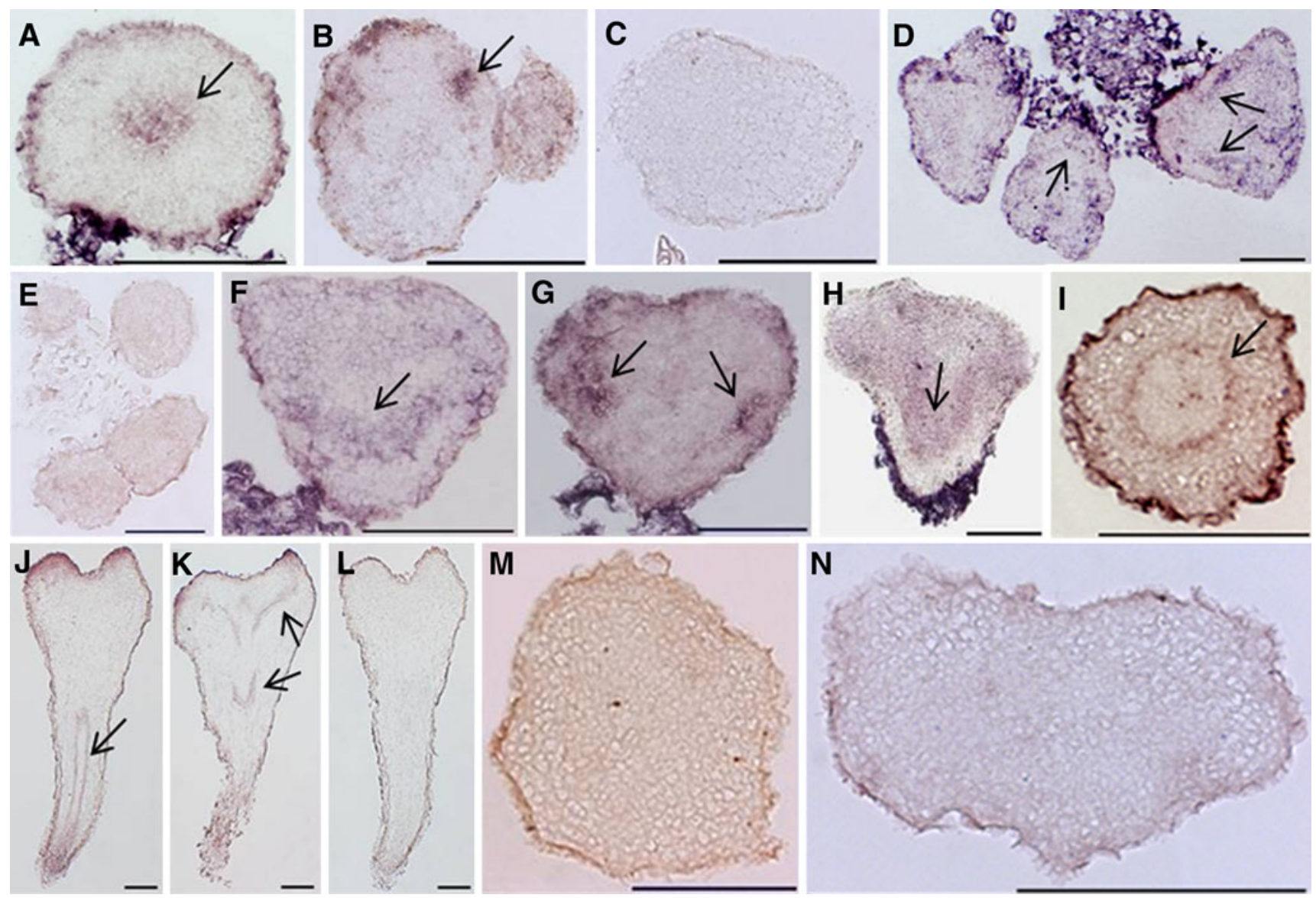

Fig. 4 In situ localization of $C s S C R$ mRNA in cucumber somatic embryos. A hybridization signal (arrows) was observed in the globular (a, b), heart $(\mathbf{d}, \mathbf{f}, \mathbf{g})$, torpedo (h) and mature (i-l) embryo stages. In a transverse section of the root part of mature somatic embryos, a signal was observed in the endodermis layer (i), but no signal was observed in the apical part (n). See text for a detailed

divisions of the resulting daughter cells. Anticlinal divisions were also observed in the endodermis, cortex and procambium cells in the area of primordium initiation.

\section{CsSCR transcript localization in primary and lateral roots}

Cucumber roots obtained from seedlings were processed for in situ hybridization. Microscopic examination of longitudinal sections through primary and lateral roots indicated that $C s S C R$ transcripts were localized in a single cell layer (Fig. 6) surrounding the stele, corresponding to the endodermis identified by histological analysis (Fig. 6). Signals were also observed in initial cells of the endodermis and cortex and in the QC (Fig. 6a, e). After the periclinal division of an initial cell, the CSSCR transcript accumulation was restricted to an inner cell layer, the proendodermis, and the signal disappeared from the outer cell layer. In transverse sections, CSSCR transcripts were localized in a description. a-c Globular stage. d-g Heart stage. h Early torpedo stage. i-n Mature stage. $\mathbf{f}-\mathbf{h}, \mathbf{j}-\mathbf{l}$ Longitudinal sections. $\mathbf{i}, \mathbf{m}$, n Transverse sections. In situ hybridization was carried out using antisense $(\mathbf{a}, \mathbf{b}, \mathbf{d}, \mathbf{f}-\mathbf{l}, \mathbf{n})$ and sense $(\mathbf{c}, \mathbf{e}, \mathbf{m})$ cRNA probes. The scale bars represent $100 \mu \mathrm{m}$

single cell layer surrounding the vascular cylinder (Fig. 6c) that corresponded to the endodermis in the histological transverse section (Fig. 5d). In the early stages of developing LRP, CsSCR transcripts were localized in two layers derived from pericycle cells and in the single layer of endodermis (Fig. 5f). In longitudinal sections through later developmental stages of LRP, signals were detected in a single cell layer (Fig. 6g). In a transverse section of primordia protruding over the root surface, signal localization was similar to that seen in primary root and was restricted to the endodermis (Fig. 6h). No signals were observed after hybridization with a sense probe (Fig. 6b, d).

GUS activity driven by the CSSCR promoter in cucumber somatic embryos and in roots of mature plants

The activity of the CsSCR promoter was examined using fusions with the uidA reporter gene in transgenic T0 somatic 


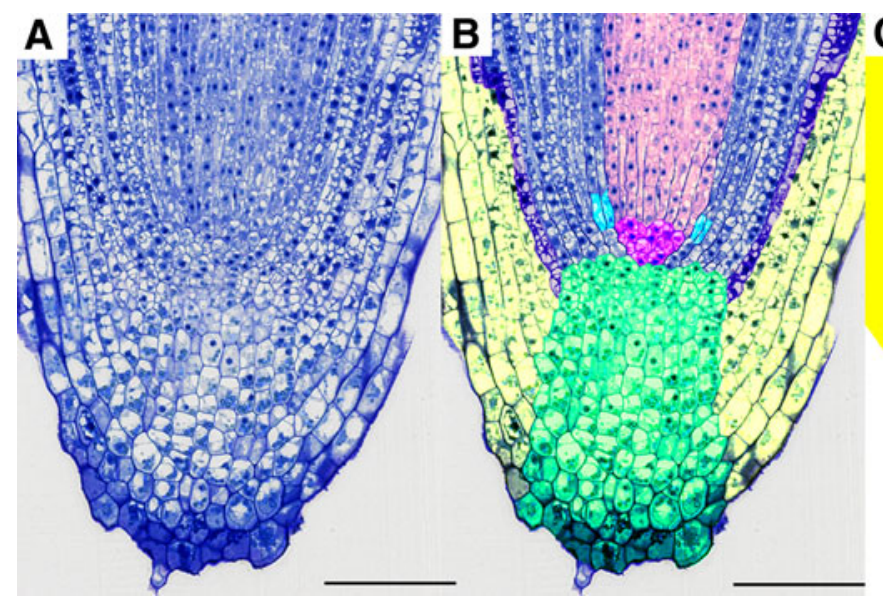

Fig. 5 The organization of C. sativus RAM conforms to open OtvD type. a Central longitudinal section, b the same section with cell lineages marked, c cell lineages, $\mathbf{d}$ transverse section through the primary root. The different cell types are indicated by colours: procambium and its initials (pink), primary root cortex (noncoloured), endodermis and inner layer of cortex parenchyma lineages

embryos, roots developed from these embryos and in seven mature regenerated cucumber plants. GUS activity was detected in some sectors of cytokinin-dependent embryogenic suspension (ECS) aggregates (Fig. 7a). In early stage somatic embryos, GUS staining was observed along the apical-basal axis, and in both shoot and root areas of 14-dayold embryos (Fig. 7b-d). At the heart and subsequent somatic embryo stages, no expression was visible in the shoot apical meristem. In some cucumber plantlets derived from somatic embryos, GUS activity was detected in shoot apical meristem regions, which disappeared in the fully developed plants. In mature transgenic plants, GUS staining was observed in root apical and lateral meristems, lateral root primordia, root quiescent centre cells and putative endodermal cells (Fig. 7e-k). The differences between the GUS activity driven by $1.7 \mathrm{kbp} C S S C R$ promoter and in situ signals in the root tips can be a result of tissue-specific differences in the stability of GUS and CsSCR mRNA, and/or a loss of specific cis-regulatory elements and/or posttranscriptional gene expression regulation.

\section{Discussion}

In this study, we examined the structure of the CsSCR gene, its relationship to 36 cucumber paralogues and its expression during somatic embryogenesis. Our results, together with those obtained in other species, indicate that SCR proteins likely perform a highly conserved function in root radial patterning.

The structural features of all known $S C R$ genes are similar. The four genes compared in this study, originating from

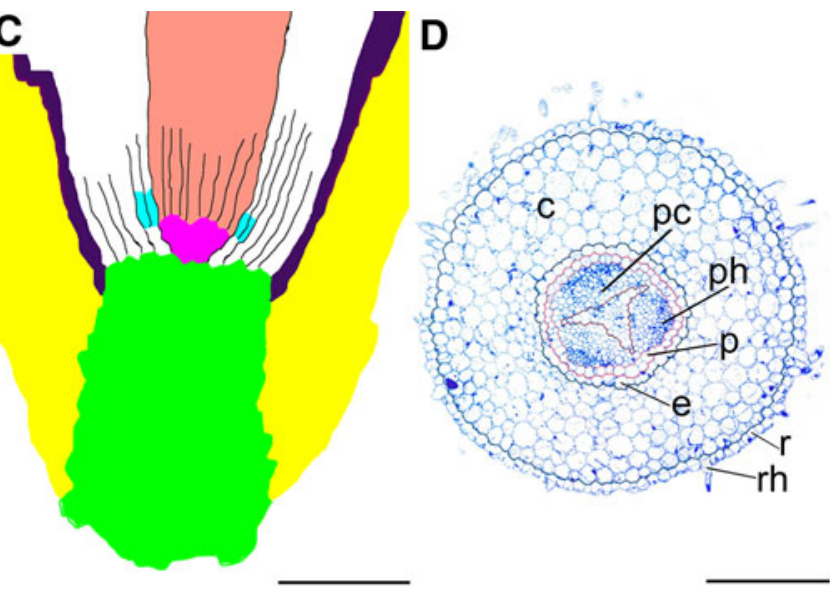

first discernible (blue), rhizodermis lineage (violet), root cap lateral cells (yellow), columella and its initials (green) and putative location of QC (purple). $c$ cortex, $e$ endodermis, $p$ pericycle, $p c$ procambium, $p h$ phloem, $r$ rhizodermis, $r h$ root hair. The scale bars represent $100 \mu \mathrm{m}$

A. thaliana, P. sativum, Z. mays and C. sativus, each contain one intron at the same position. So far, only the pine PsySCR gene has been shown to lack this intron. Laajanen et al. (2007) suggested that the intron was introduced into the angiosperm genome after their divergence from gymnoperms, but alternatively, it might have been lost in this phylogenetic lineage. The introns of the aforementioned $S C R$ genes are variable in length, which is in contrast to the highly conserved second exon, that has the same length in all known SCR genes. The nucleotide similarity among GRAS family members in cucumber appears to be low. Southern blot analysis using a molecular probe specific to a region encoding a conserved domain confirmed that there are no closely related paralogues of the CSSCR gene in the cucumber genome. This is in contrast to white lupin, in which two highly similar SCS genes, that play a role during cluster root development, were identified (Sbabou et al. 2010).

The putative protein encoded by the CSSCR gene has five conserved C-terminal domains that are characteristic of the GRAS transcription factor family: LHRI, VHIID, LHRII, PFYRE and SAW (Pysh et al. 1999; Tian et al. 2004). The VHIID domain is probably responsible for interaction with DNA, LHRI and LHRII mediate proteinprotein dimerization (Pysh et al. 1999; Lim et al. 2000, Tian et al. 2004), while the PFYRE and SAW domains have putative regulatory functions (Itoh et al. 2002). The presence of an $\mathrm{N}$-terminal homopolymeric region is also characteristic of the GRAS protein family. Sequence similarity in this region is very low but some characteristic stretches of amino acids were detected in CsSCR. For example, the proline and serine repeats that are abundant in CsSCR are typical of transcription factor activation 

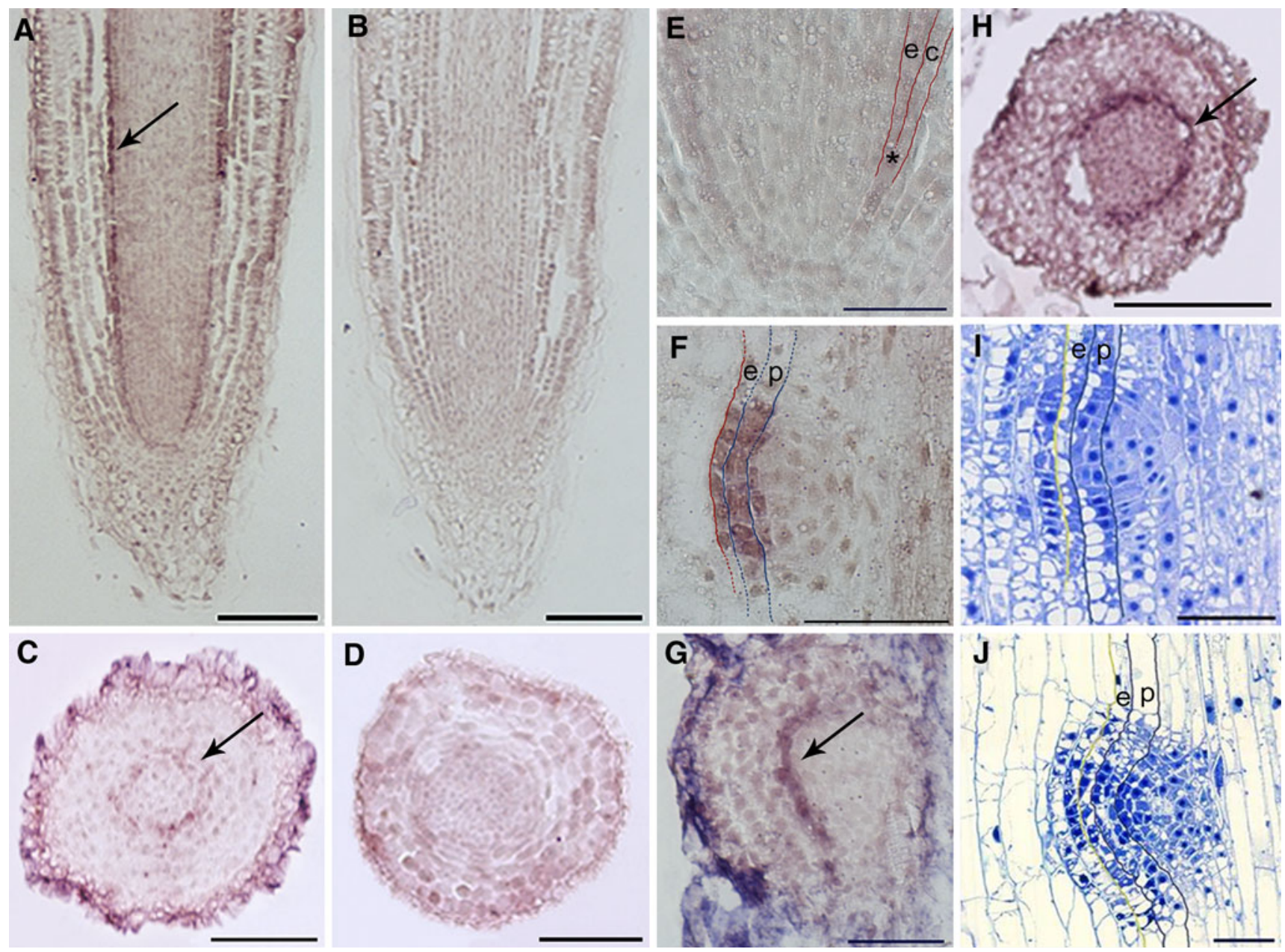

Fig. 6 In situ localization of $C S S C R$ transcripts and anatomy of lateral roots of cucumber seedlings. In situ hybridization of a CsSCR antisense probe with longitudinal (a) and transverse (c) sections of the primary root. CSSCR transcripts were localized in the endodermis (arrows). No signals were observed after in situ hybridization of a CsSCR sense probe with longitudinal (b) or transverse (d) sections. In situ hybridization of a $C S S C R$ antisense probe with longitudinal sections of the root meristem (e). CsSCR transcripts were localized in the endodermis/cortex initial cell endodermis (star), and in the

domains (Johnson et al. 1993). These features of the CsSCR protein strongly suggest that it plays a role in transcription regulation similar to AtSCR.

Phylogenetic analyses showed that CsSCR is the most similar of the 36 cucumber CsSCL proteins to AtSCR. It is also the most similar to AtSCR among 47 known GRAS proteins from different species, and resides within the same clade as other SCARECROW proteins.

An analysis of CsSCR transcript accumulation showed that its expression is upregulated in SE and roots, in contrast to ECS. Based on this finding and known AtSCR functions, we postulated that the CSSCR gene might act in the regulation of radial patterning of root tissue, from the earliest stages of plant development. To test this hypothesis,

endodermis after division. In situ localization of $C S S C R$ transcripts in a developing lateral root primordium (f), developed root primordium (g) and transverse section of a young lateral root (h). Signals were observed in the pericycle and endodermis in the developing primordium (f) and in the endodermis in the subsequent stages (arrows $\mathbf{g}, \mathbf{h}$ ). Anatomy of developing lateral root primordia $(\mathbf{i}, \mathbf{j})$. Lines separate the endodermis $(e)$ and pericycle $(p)$ layers. $c$ cortex. The scale bars represent $50(\mathbf{e}, \mathbf{f}, \mathbf{i}, \mathbf{j})$ or $100 \mu \mathrm{m}(\mathbf{a}-\mathbf{d}, \mathbf{g}, \mathbf{h})$

we performed a more detailed examination of $C S S C R$ expression in cucumber somatic embryos, and primary and lateral plant roots.

Scheres et al. (1995) identified four mutants with different abnormalities in root growth. One of them, scr, had a radial pattern defect, both in the root and the hypocotyl. The cellular patterning of the scr mutant was noticeably different from the wild type, starting from the early heart stage. In torpedo stage embryos the defects were clearly visible due to the absence of one layer between the pericycle and the epidermis - the endodermis. In cucumber, CSSCR transcripts were first detected in situ in globular stage somatic embryos (where there is no clear direction of cell division) and were visible as localized patches. This 

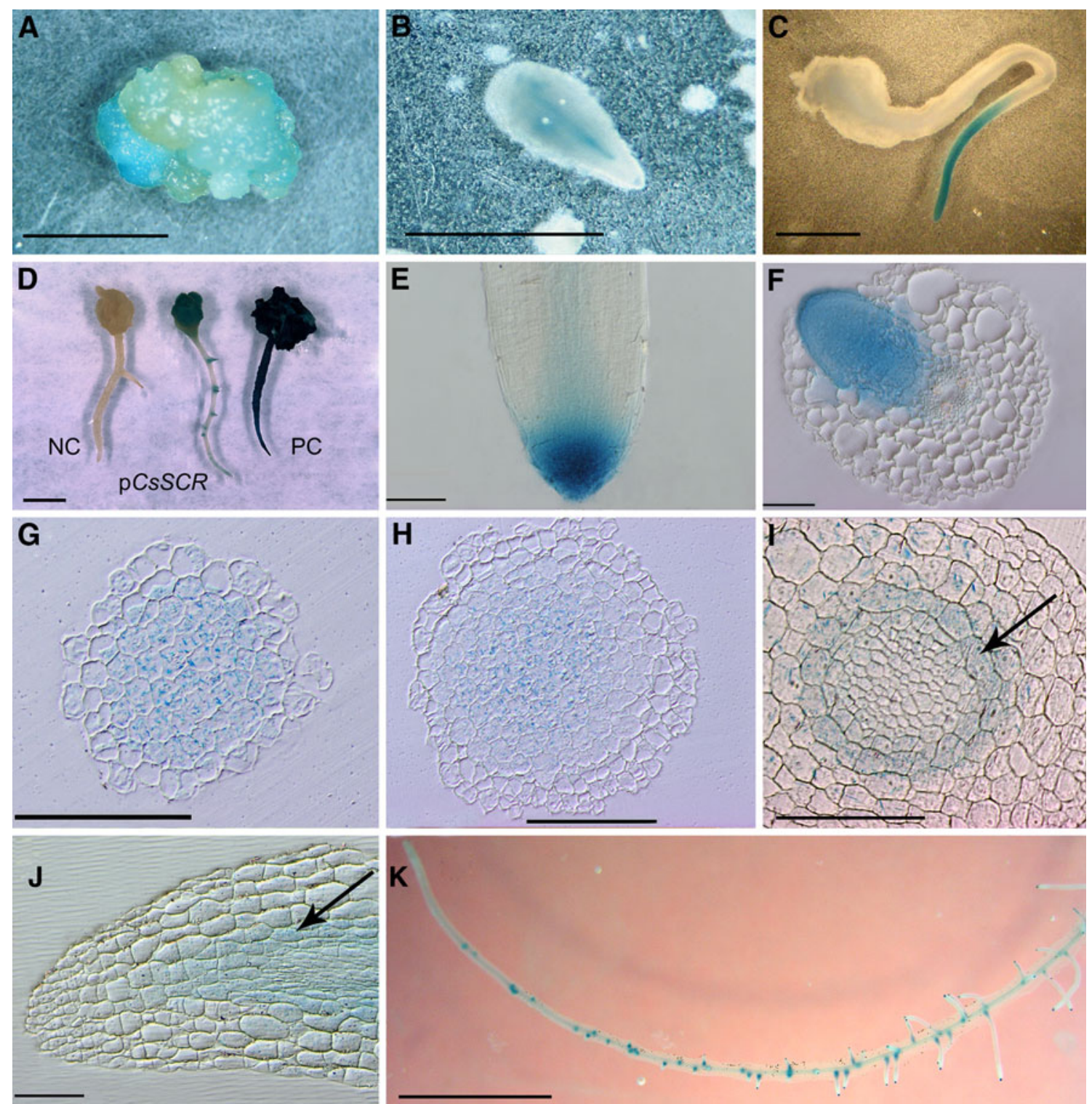

Fig. 7 CsSCR promoter activity in ECS aggregates (a), torpedo- (b), 10-day-old- (c), and 14-day-old (d, centre) somatic embryos, and cucumber roots $(\mathbf{e}-\mathbf{k})$. GUS activity was detected in some areas of ECS aggregates (a), in younger somatic embryos along the apicalbasal axis (b), in the root part of 10-day-old embryos (c), and in shoot and root meristems and primordia of 14-day-old embryos (d, centre). d left somatic embryo induced from non-transformed ECS, negative control (NC). d right somatic embryo developed from ECS carrying the uidA gene under $35 \mathrm{~S}$ promoter control, positive control (PC).

patchy appearance indicated the direction of polarization of globular shaped embryos and the location of shoot and root poles, and the establishment of an embryo axis. It appears that in globular somatic embryos, before apical-basal axis formation, some cells undergo differentiation and show expression of the root marker gene Scarecrow. These cells might be equivalent to hypophyseal cell progeny of zygotic embryos, since the earliest $S C R$ expression detected in A. thaliana was in the hypophyseal cell lineage preceding
CSSCR promoter activity was observed in the meristems of primary (e, fresh root) and lateral (f) roots. Transverse sections of the meristematic zone of primary root with GUS activity visible in initial cells (g, h). CsSCR promoter activity (arrows) in cells of the endodermis layer in transverse (i) and longitudinal (j) sections of the root elongation zone. $C S S C R$ promoter activity was detected in the apical root meristem, lateral root meristems, lateral root primordia and internal root tissues in adult cucumber plant roots (k). The scale bars represent $5 \mathrm{~mm}(\mathbf{a}-\mathbf{d}), 100 \mu \mathrm{m}(\mathbf{e}-\mathbf{j})$ or $10 \mathrm{~mm}(\mathbf{k})$

its division to generate the quiescent centre and the root cap (Wysocka-Diller et al. 2000). Consequently, the similarities of CSSCR to its Arabidopsis orthologue are likely to extend to a role in root radial patterning. This conclusion is supported by the localization of CsSCR mRNA during cucumber development from early somatic embryos to the roots of the adult plant.

The expression of the CSSCR gene was localized in the root meristem and the endodermis of mature embryos, 
similar to that of AtSCR. During A. thaliana embryo development, AtSCR expression was detected in the ground tissue of late heart stage embryos. After the initial cell division of the ground tissue, expression was only detected in the endodermis (Di Laurenzio et al. 1996). Evidence of a direct requirement for SCR activity in QC cells for their specification and the maintenance of surrounding stem cells was provided by Sabatini et al. (2003). Based on these results we suppose that the role of $S C R$ in the regulation of divisions of initial cells and endodermis differentiation is similar in both Arabidopsis and cucumber.

A. thaliana, the species in which the SCR gene has been most intensively studied, has closed root meristem in contrast to the basic-open type of root meristem in cucumber. This type of root meristem is found only in two families: the Fabaceae and Cucurbitaceae. In open root meristems there is no clearly defined boundary between the root proper and the root cap, which can cause some difficulties when tracking cell files and their initials (Rost 2011).

However, the pattern of CsSCR expression in cucumber root appeared to be similar to that of $S C R$ s from other species with the open root type (P. sativum, L. albus) and the closed root type (A. thaliana, Z. mays, O. sativa, I. nil, P. sylvestris) (Heimsch and Seago 2008), which indicates that $S C R$ genes function independently of the type of root.

Scheres et al. (1995) postulated that the radial pattern of lateral roots is mediated by the same genes that are activated in the embryo, and A. thaliana SCR also acts in lateral roots and roots regenerated from calli (Di Laurenzio et al. 1996).

Lateral roots usually develop postembryonically. Cucumber is a rare example of a plant in which LRP initiation starts on the primary root during embryo development and these primordia are well developed in mature embryos (Dubrovsky and Rost 2003). The initiation of LRP occurs in a few pericycle cells (founder cells) located near the protoxylem poles and can be activated by environmental factors (Dubrovsky et al. 2000). Founder cells undergo asymmetric anticlinal divisions and form initial cells, which further divide in the periclinal manner to produce two layers of pericycle near the developing primordium. Based on the localization of CsSCR transcripts in these two pericycle layers in cucumber LRP, we postulate that $C S S C R$ is responsible for the regulation of asymmetric divisions in initial cells of LRP. SCR-dependent regulation of an asymmetric cell division has also been documented in A. thaliana (Di Laurenzio et al. 1996) and Oryza sativa (Kamiya et al. 2003).

Based on the results of the present study, particularly the high sequence similarity to other SCR proteins and the expression pattern of $C S S C R$ during embryo and root development, we postulate that CsSCR is a functional orthologue of AtSCR. This is the first report to focus on $S C R$ gene in the cucurbit family, as well as the first detailed description of root anatomy in cucumber.

Author contribution A.W., S.M. and M.F. designed the experiments and wrote the manuscript. A.P.-B., N.T. and B.Ł. participated in in situ hybridization and analysis of cucumber root anatomy. S.Z. did cucumber transformation and provided inputs to improve the manuscript. A.W. performed the rest of experiments, collected and analysed data. All authors have read and approved the final manuscript.

Acknowledgments We are indebted to Alice J. Paquette and Philip N. Benfey (Duke University, Durham, USA) for information about the AtSCR gene and their helpful suggestions. We also thank Magdalena Krzymowska and Jacek Hennig (Institute of Biochemistry and Biophysics, PAS, Poland), and Sylwia Fudali (Warsaw University of Life Sciences, Poland), for help and valuable discussions and Adam Wiśniewski for graphical assistance. All sequence data (with the exception of the CsSCR gene) were produced by the Polish Consortium of Cucumber Genome Sequencing (http://csgenome.sggw.pl). This work was supported by grants from the Ministry of Science and Higher Education in Poland (PBZ/KBN/029/P06/2000 and 3P06A02425).

Open Access This article is distributed under the terms of the Creative Commons Attribution License which permits any use, distribution, and reproduction in any medium, provided the original author(s) and the source are credited.

\section{References}

Ahmed KZ, Sagi F (1993) High-efficiency plant regeneration from an embryogenic cell suspension culture of winter wheat (Triticum aestivum L.). Acta Biol Hung 44:421-432

Altschul SF, Madden TL, Schaffer AA, Zhang J, Zhang Z, Miller W, Lipman DJ (1997) Gapped BLAST and PSI-BLAST: a new generation of protein database search programs. Nucleic Acids Res 25:3389-3402

Benfey PN, Linstead PJ, Roberts K, Schiefelbein JW, Hauser MT, Aeschbacher RA (1993) Root development in Arabidopsis: four mutants with dramatically altered root morphogenesis. Development 119:57-70

Bolle C (2004) The role of GRAS proteins in plant signal transduction and development. Planta 218:683-692

Bozhkov PV, Filonova LH, von Arnold S (2002) A key developmental switch during Norway spruce somatic embryogenesis is induced by withdrawal of growth regulators and is associated with cell death and extracellular acidification. Biotechnol Bioeng 77:658-667

Burza W, Zuzga S, Yin Z, Malepszy S (2006) Cucumber (Cucumis sativus L.). In: Wang K (ed) Methods in molecular biology 343 Agrobacterium protocols, vol 1. Humana Press, Totowa, NJ, pp 427-438

Cui H, Levesque MP, Vernoux T, Jung JW, Paquette AJ, Gallagher KL, Wang JY, Blilou I, Scheres B, Benfey PN (2007) An evolutionarily conserved mechanism delimiting SHR movement defines a single layer of endodermis in plants. Science 316:421-425 
Di Laurenzio L, Wysocka-Diller J, Malamy JE, Pysh L, Helariutta Y, Freshour G, Hahn MG, Feldmann KA, Benfey PN (1996) The SCARECROW gene regulates an asymmetric cell division that is essentials for generating the radial organization of the Arabidopsis root. Cell 96:423-433

Dubrovsky JG, Rost TL (2003) Root development/lateral root initiation. In: Thomas B, Murphy DJ, Murray B (eds) Encyclopedia of applied plant science. Elsevier, pp 1101-1107

Dubrovsky JG, Doerner PW, Colón-Carmona A, Rost TL (2000) Pericycle cell proliferation and lateral root initiation in Arabidopsis. Plant Physiol 124:1648-1657

Filipecki MK, Sommer H, Malepszy S (1997) The MADS-box gene CUS1 is expressed during cucumber somatic embryogenesis. Plant Sci 125:63-74

Fujimura T, Komamine A (1979) Synchronization of somatic embryogenesis in a carrot cell suspension culture. Plant Physiol 64:162-164

Grabowska A, Wisniewska A, Tagashira N, Malepszy S, Filipecki M (2009) Characterization of CsSEF1 gene encoding putative $\mathrm{CCCH}$-type zinc finger protein expressed during cucumber somatic embryogenesis. J Plant Physiol 166:310-323

Gubler F, Jacobsen JV (1992) Gibberellin-responsive elements in the promoter of a barley high-pI alpha-amylase gene. Plant Cell 4:1435-1441

Hattori T, Vasil V, Rosenkrans L, Hannah LC, McCarty DR, Vasil IK (1992) The Viviparous-1 gene and abscisic acid activate the C1 regulatory gene for anthocyanin biosynthesis during seed maturation in maize. Genes Dev 6:609-618

Heidstra R, Welch D, Scheres B (2004) Mosaic analyses using marked activation and deletion clones dissect Arabidopsis SCARECROW action in asymmetric cell division. Genes Dev 18:1964-1969

Heimsch C, Seago JL (2008) Organization of the root apical meristem in angiosperms. Am J Bot 95:1-21

Helariutta Y, Fukaki H, Wysocka-Diller J, Nakajima K, Jung J, Sena G, Hauser MT, Benfey PN (2000) The SHORT-ROOT gene controls radial patterning of the Arabidopsis root through radial signaling. Cell 101:555-567

Higo K, Ugawa Y, Iwamoto M, Korenaga T (1999) Plant cis-acting regulatory DNA elements PLACE database. Nucleic Acids Res 27:297-300

Hobo T, Asada M, Kowyama Y, Hattori T (1999) ACGT-containing abscisic acid response element (ABRE) and coupling element 3 (CE3) are functionally equivalent. Plant J 19:679-689

Itoh H, Ueguchi-Tanaka M, Sato Y, Ashikari M, Matsuoka M (2002) The gibberellin signaling pathway is regulated by the appearance and disappearance of SLENDER RICE1 in nuclei. Plant Cell 14:57-70

Itzhaki H, Maxson JM, Woodson WR (1994) An ethylene responsive enhancer is involved in the senescence-related expression of the carnation glutathione- $S$-transferase (GST1) gene. Proc Natl Acad Sci USA 91:8925-8929

Jefferson RA, Kavanagh TA, Bevan MW (1987) GUS fusions: betaglucuronidase as a sensitive and versatile gene fusion marker in higher plants. EMBO J 6:3901-3907

Johnson PF, Sterneck E, Williams SC (1993) Activation domains of transcriptional regulatory proteins. J Nutr Biochem 4:386-398

Kamiya N, Itoh JI, Morikami A, Nagato Y, Matsuoka M (2003) The SCARECROW gene's role in asymmetric cell divisions in rice plants. Plant J 36:45-54

Laajanen K, Vuorinen I, Salo V, Juuti J, Raudaskoski M (2007) Cloning of Pinus sylvestris SCARECROW gene and its expression pattern in the pine root system, mycorrhiza and NPA-treated short roots. New Phytol 175:230-243

Lanahan MB, Ho TH, Rogers SW, Rogers JC (1992) A gibberellin response complex in cereal alpha-amylase gene promoters. Plant Cell 4:203-211
Lescot M, Déhais P, Moreau Y, De Moor B, Rouzé P, Rombauts S (2002) PlantCARE: a database of plant cis-acting regulatory elements and a portal to tools for in silico analysis of promoter sequences. Nucleic Acids Res 30:325-327

Lim J, Helariutta Y, Szpecht CD, Jung J, Sims L, Bruce WB, Diehl S, Benfey PN (2000) Molecular analysis of the SCARECROW gene in maize reveals a common basis for radial pattering in diverse meristem. Plant Cell 12:1307-1318

Lim J, Jung JW, Lim CE, Lee MH, Kim BJ, Kim M, Bruce WB, Benfey PN (2005) Conservation and diversification of SCARECROW in maize. Plant Mol Biol 59:619-630

Lincoln C, Long J, Yamaguchi J, Serikawa K, Hake S (1994) A knotted1-like homeobox gene in Arabidopsis is expressed in the vegetative meristem and dramatically alters leaf morphology when overexpressed in transgenic plants. Plant Cell 6:1859-1876

Linkiewicz A, Filipecki M, Tomczak A, Grabowska A, Malepszy S (2004) The cloning of sequences differentially transcribed during the induction of somatic embryogenesis in cucumber (Cucumis sativus L.). Cell Mol Biol Lett 9:795-804

Malinowski R, Filipecki M, Tagashira N, Wiśniewska A, Gaj P, Pląder W, Malepszy S (2004) Xyloglucan endotransglucosylase/ hydrolase genes in cucumber (Cucumis sativus) - differential expression during somatic embryogenesis. Physiol Plant 120: $678-685$

Matys V, Fricke E, Geffers R, Gößling E, Haubrock M, Hehl R, Hornischer K, Kel AE, Kel-Margoulis OV, Kloos DU, Land S, Lewicki-Potapov B, Michael H, Münch R, Reuter I, Rotert S, Saxel H, Scheer M, Thiele S, Wingender E (2003) TRANSFAC: transcriptional regulation, from patterns to profiles. Nucleic Acids Res 31:374-378

Mena M, Cejudo FJ, Isabel-Lamoneda I, Carbonero P (2002) A role for the DOF transcription factor BPBF in the regulation of gibberellin-responsive genes in barley aleurone. Plant Physiol 130:111-119

Montgomery J, Goldman S, Deikman J, Margossian L, Fischer RL (1993) Identification of an ethylene-responsive region in the promoter of a fruit ripening gene. Proc Natl Acad Sci USA 90:5939-5943

Morita A, Umemura T, Kuroyanagi M, Futsuhara Y, Perata P, Yamaguchi J (1998) Functional dissection of a sugar-repressed alpha-amylase gene (RAmy1A) promoter in rice embryos. FEBS Lett 423:81-85

Nakajima K, Sena G, Nawy T, Benfey PN (2001) Intercellular movement of the putative transcription factor SHR in root patterning. Nature 413:307-311

Nei M, Kumar S (2000) Molecular evolution and phylogenetics. Oxford University Press, New York

Peng J, Richards DE, Moritz T, Caño-Delgado A, Harberd NP (1999) Extragenic suppressors of the Arabidopsis gai mutation alter the dose-response relationship of diverse gibberellin responses. Plant Physiol 119:1199-1208

Pysh LD, Wysocka-Diller JW, Camilleri C, Bouchez D, Benfey PN (1999) The GRAS gene family in Arabidopsis: sequence characterization and basic expression analysis of the SCARECROW-LIKE genes. Plant J 18:111-119

Rice P, Longden I, Bleasby A (2000) EMBOSS: the European molecular biology open software suite. Trends Genet 16:276-277

Rost TL (2011) The organization of roots of dicotyledonous plants and the positions of control points. Ann Bot 107:1213-1222

Sabatini S, Heidstra R, Wildwater M, Scheres B (2003) SCARECROW is involved in positioning the stem cell niche in the Arabidopsis root meristem. Genes Dev 17:354-358

Sassa N, Matsushita Y, Nakamura T, Nyunoya H (2001) The molecular characterization and in situ expression pattern of pea SCARECROW gene. Plant Cell Physiol 42:385-394

Sbabou L, Bucciarelli B, Miller S, Liu J, Berhada F, Filali-Maltouf A, Allan D, Vance C (2010) Molecular analysis of SCARECROW 
genes expressed in white lupin cluster roots. J Exp Bot 61:1351-1363

Scheres B, Di Laurenzio L, Willemsen V, Hauser MT, Janmaat K, Weisbeek P, Benfey PN (1995) Mutations affecting the radial organisation of the Arabidopsis root display specific defects throughout embryonic axis. Development 121:53-62

Silverstone AL, Ciampaglio CN, Sun T (1998) The Arabidopsis RGA gene encodes a transcriptional regulator repressing the gibberellin signal transduction pathway. Plant Cell 10:155-169

Tamura K, Dudley J, Nei M, Kumar S (2007) MEGA4: molecular evolutionary genetics analysis (MEGA) software version 40 . Mol Biol Evol 24:1596-1599

Tian C, Wan P, Sun S, Li J, Chen M (2004) Genome-wide analysis of the GRAS gene family in rice and Arabidopsis. Plant Mol Biol 54:519-532

Torres-Galea P, Huang LF, Chua NH, Bolle C (2006) The GRAS protein SCL13 is a positive regulator of phytochrome-dependent red light signaling, but can also modulate phytochrome A responses. Mol Genet Genomics 276:13-30

Wiśniewska A, Grabowska A, Pietraszewska-Bogiel A, Tagashira N, Zuzga S, Wóycicki R, Przybecki Z, Malepszy S, Filipecki M (2012) Identification of genes up-regulated during somatic embryogenesis of cucumber. Plant Physiol Biochem 50:54-64
Wóycicki R, Witkowicz J, Gawroński P, Dąbrowska J, Lomsadze A, Pawełkowicz M, Siedlecka E, Yagi K, Pląder W, Seroczyńska A, Śmiech M, Gutman, W, Niemirowicz-Szczytt K, Bartoszewski G, Tagashira N, Hoshi Y, Borodovsky M, Karpiński S, Malepszy S, Przybecki Z (2011) The genome sequence of the NorthEuropean cucumber (Cucumis sativus L.) unravels evolutionary adaptation mechanisms in plants. PLoS ONE 6:e22728. doi: 10.1371/journal.pone.0022728

Wróblewski T, Filipecki M, Malepszy S (1995) Factors influencing cucumber (Cucumis sativus L.) somatic embryogenesis I. The crucial role of $\mathrm{pH}$ and nitrogen in suspension culture. Acta Soc Bot Pol 64:223-231

Wu C, Washida H, Onodera Y, Harada K, Takaiwa F (2000) Quantitative nature of the prolamin-box, ACGT and AACA motifs in a rice glutelin gene promoter: minimal cis-element requirements for endosperm-specific gene expression. Plant $\mathbf{J}$ 23:415-421

Wysocka-Diller J, Helariutta Y, Fukaki H, Malamy J, Benfey PN (2000) Molecular analysis of SCARECROW function reveals a radial pattering mechanism common to root and shoot. Development 127:595-603 